Syntax Fusion : Jurnal Nasional Indonesia

p-ISSN: -

e-ISSN : 2775-4440

Vol. 1, No. 8, Agustus 2021

\title{
HUBUNGAN PENGETAHUAN IBU HAMIL TRIMESTER I DENGAN SIKAP IBU HAMIL DALAM MELAKUKAN PEMERIKSAAN ANC TERPADU
}

\section{Indah Rahayu}

Sekolah Tinggi Kesehatan Indonesia Wirautama Bandung

Email : indahfakhri.fakhrizal@gmail.com

\begin{abstract}
Abstrak
Pemeriksaan ANC terpadu merupakan upaya preventif untuk memantau kemajuan kehamilan dan mendeteksi komplikasi, sebagian besar kehamilan dan persalinan merupakan kejadian yang fisiologis, dan hanya sebagian kecil saja yang menjadi patologis, namun kehamilan dan persalinan yang normal pun dapat menjadi patologis apabila tidak di tangani secara benar, oleh sebab itu ibu hamil sangat penting melakukan pemeriksaan ANC terpadu karena dengan melakukan pemeriksaan ANC terpadu akan dapat di deteksi apabila kehamilan tersebut patologis. Untuk mengetahui hubungan pengetahuan ibu hamil trimester I dengan sikap ibu hamil dalam melakukan pemeriksaan ANC terpadu. Metode penelitian yang digunakan adalah korelasi, dengan desain penelitian Cross Sectional. Pada penelitian ini yang menjadi variabel independen adalah pengetahuan ibu hamil trimester I tentang pentingnya melakukan pemeriksaan ANC terpadu sedangkan variabel dependen yaitu sikap ibu hamil trimester I tentang pentingnya melakukan ANC terpadu. Teknik pengambilan sampel yang digunakan adalah total sampling, dengan jumlah 45 sampel. Analisis data yang digunakan adalah chi-square dengan menggunakan program Statistical Product and Service Solution (SPSS). Hasil penelitian menunjukan sebagian besar ibu hamil trimester I berpengetahuan kurang 51,1\%, dan sebagian besar sikap ibu hamil trimester I bersikap negatif 75,6\% tentang pentingnya melakukan pemeriksaan ANC terpadu. Ada hubungan pengetahuan ibu hamil trimester I dengan sikap ibu hamil dalam melakukan pemeriksaan ANC terpadu.
\end{abstract}

Kata Kunci : ANC Terpadu, Hubungan, Pengetahuan, Sikap,

\section{Pendahuluan}

Angka Kematian Ibu (AKI) tahun 2019 di Indonesia masih terhitung tinggi, yaiti 305 ibu per 100.000 kelahiran ibu yang hidup. Angka yang muncul hampir 30 persen itu masih dianggap tinggi jika dibandingkan dengan negara tetangga, yaitu Malaysia, yang 
tehitung hanya 17 per 100.000 kelahiran hidup dalam data pada tahun yang sama. Dalam upaya untuk mendukung penurunan angka kematian ibu dan angka kamatian bayi, maka mesti dilaksanakan kegiatan pelayanan kesehatan ibu, pelayanan kesehatan bayi dan balita, serta pelayanan kesehatan reproduksi dan keluarga berencana, baik di tingkat paling bawah yaitu masyarakat, Puskesmas dan Rumah Sakit, sampai dengan melibatkan lintas program dan lintas sektor terkait serta jejaring lain.

Kehamilan merupakan waktu yang sangat membahagiakan bagi seorang perempuan dalam satu masa di tahapan kehidupannya, dan merupakan anugerah yang luar biasa, karena saat itulah seorang perempuan bisa mengalirkan emosi cintanya kepada calon buah hatinya. Dalam hal ini, Ante Natal Care (perawatan selama kehamilan) menjadi satu bagian yang mestinya tidak terpisahkan dalam mengupayakan kehamilan yang sehat, baik bagi ibu maupun bagi calon bayi.

Sebelumnya, patut dipahami jika setiap perempuan hamil mempunyai risiko komplikasi dan mestinya mempunyai akses terhadap pelayanan kesehatan kehamilan, persalinan, dan nifas yang berkualitas baik. Bahkan perempuan yang masuk dalam kelompok dengan resiko rendah pun, masih bisa saja mengalami komplikasi. Sehingga mestinya pelayanan antenatal sudah selayaknya dilaksanakan secara komprehensif diberikan kepada setiap ibu hamil, untuk memastikan bahwa kehamilan tersebut berlangsung dengan normal, dan mampu mendeteksi dini masalah dan penyakit yang akan dialami oleh seorang ibu.

Banyak cara untuk menyelamatkan ibu hamil mati saat melahirkan, dan salah satu upayanya adalah dengan melaksanakan pemeriksaan kehamilan melalui Antenatal Terpadu Berkualitas (ATB). ATB merupakan penyempurnaan pelayanan ANC dengan menggunakan berbagai sumber daya yang tersedia di fasilitas pelayanan kesehatan dasar, seperti di dokter umum, pemeriksaan gigi dan pemeriksaan laboratorium. Dengan pelayanan ANC terpadu tersebut, didorong agar pelayanan ANC lebih berkualitas dengan melengkapi pemeriksaan kehamilan.

Sebagian besar kehamilan dan persalinan merupakan kejadian yang fisiologis, dan hanya sebagian kecil saja yang menjadi patologis, namun kehamilan dan persalinan yang normal pun dapat menjadi patologis apabila tidak ditangani secara benar. Terutama pada ibu hamil trimester I, pengetahuan ibu hamil trimester I tentang pemeriksaan ANC terpadu sangat penting, karena apabila pada trimester I pengetahuan ibu hamilnya baik tentang pemeriksaan ANC terpadu maka diharapkan sikap ibu hamil akan baik dalam melakukan ANC terpadu.

\section{Metode Penelitian}

Metode penelitian yang digunakan di dalam penelitian ini adalah Metode Korelasi, yaitu metode yang pada hakikatnya merupakan penelitian atau penelaahan hubungan antara dua variabel. Dalam penelitian kali ini dua variable itu adalah pengetahuan ibu hamil trimester I dengan sikap ibu hamil dalam melakukan pemeriksaan ANC terpadu. 
Metode penelitian ini menggunakan pendekatan cross sectional, yaitu data yang menyangkut variabel bebas atau risiko dan variabel terikat atau variabel akibat, akan dikumpulkan dalam waktu yang bersamaan. Dalam hali ini pengetahuan ibu hamil trimester I dengan sikap ibu hamil dalam melakukan pemeriksaan ANC terpadu.

\section{Hasil dan Pembahasan}

Pengetahuan ibu hamil trimester I tentang pemeriksaan ANC terpadu dibagi menjadi 3 kategori, yaitu baik, cukup, kurang. Berikut adalah tabel distribusi frekuensi pengetahuan ibu hamil trimester I:

Tabel 1

Pengetahuan Ibu Hamil Trimester I

Tentang Pemeriksaan ANC Terpadu

\begin{tabular}{ccc}
\hline Pengetahuan & Frekuensi & Persentase \% \\
\hline Baik & 7 & $15,6 \%$ \\
Cukup & 15 & $33,3 \%$ \\
Kurang & 23 & $51.1 \%$ \\
\hline Total & 45 & $100 \%$
\end{tabular}

Sumber:Data Primer

Berdasarkan Tabel diatas, dapat disimpulkan bahwa dari 45 responden sebagian besar memiliki pengetahuan kurang 23 orang $(51,1 \%)$ tentang pemeriksaan ANC terpadu.

Beberapa faktor penyebab besarnya pengetahuan dengan kategori kurang dari ibu hamil trimester I tentang pemeriksaan ANC terpadu dikarenakan kurangnya komunikasi dan sumber informasi tentang pemeriksaan ANC terpadu dari tenaga kesehatan atau pun dari media lainnya.

Hasil penelitian yang dilakukan oleh Dede Astri pada tanggal 28 April 2018, yang berjudul "Hubungan Pengetahuan Dengan Sikap Ibu Hamil Tentang Kunjungan Kehamilan (ANC) di Desa Galumpit Kecamatan Tegalwaru Kabupaten Purwakarta Tahun 2014" hasil penelitian menunjukan dari 55 responden yang berpengetahuan baik sebanyak 10 responden (18,8\%) dan berpengetahuan cukup sebanyak 20 orang $(36,3 \%)$, dan yang berpengetahuan kurang sebanyak 25 orang $(45,4 \%)$.

Sikap ibu hamil trimester I dibagi menjadi 2 kategori, yaitu positif dand negatif, berikut adalah table distribusi frekuensi sikap ibu hamil trimester I:

Tabel 2

Sikap Ibu Hamil

Tentang Pemeriksaan ANC Terpadu

\begin{tabular}{ccc}
\hline Sikap & Frekuensi & Persentase \% \\
\hline Positif & 11 & $24,4 \%$ \\
Negatif & 34 & $75,6 \%$ \\
\hline
\end{tabular}




\begin{tabular}{ccc}
\hline Total & 45 & $100 \%$ \\
\hline
\end{tabular}

\section{Sumber:Data Primer}

Berdasarkan Tabel diatas, dapat disimpulkan bahwa dari 45 responden sebagian besar memiliki sikap negatif 34 orang $(75,6 \%)$ tentang pemeriksaan ANC terpadu.

Sikap merupakan konsep paling penting dalam psikologi social yang membahas unsure sikap baik sebagai individu maupun kelompok. Banyak kajian merumuskan pengertian sikap, proses terbentuknya sikap, maupun perubahan. ( Wawan, 2011:4 )

Beberapa faktor penyebab besarnya sikap dengan kategori negatif dari ibu hamil tentang pemeriksaan ANC terpadu karena dipengaruhi adanya pengetahuan yang kurang dari ibu hamil trimester I tentang pemeriksaan ANC terpadu. Untuk itu perlu dilakukan upaya dalam membentuk sikap yang positif tentang pemeriksaan ANC terpadu yaitu dengan meningkatkan pengetahuan ibu hamil trimester I tentang pemeriksaan ANC terpadu.

Hasil penelitian yang dilakukan oleh Dede Astri pada tanggal 28 April 2018, yang berjudul "Hubungan Pengetahuan Dengan Sikap Ibu Hamil Tentang Kunjungan Kehamilan (ANC) Di Desa Galumpit Kecamatan Tegalwaru Kabupaten Purwakarta Tahun 2014" hasil penelitian menunjukan dari 55 responden yang memiliki sikap positif sebanyak 23 orang $(41,8 \%)$ dan yang memiliki sikap negatif 32 orang $(58,1 \%)$.

Hasil tabulasi silang antara pengetahuan ibu hamil trimester I dengan sikap ibu hamil tentang pemeriksaan ANC terpadu terdapat pada tabel berikut

\section{Tabel 3}

Hubungan Pengetahuan Ibu Hamil Trimester I Dengan Sikap Ibu Hamil Tentang Pemeriksaan ANC terpadu

\begin{tabular}{|c|c|c|c|c|}
\hline \multirow{2}{*}{ Pengetahuan } & \multicolumn{2}{|r|}{ Sikap } & \multirow{2}{*}{ Total } & \multirow{2}{*}{$P$} \\
\hline & Positif & Negatif & & \\
\hline Baik & 5 & 2 & 7 & \\
\hline Cukup & 1 & 14 & 15 & 0,004 \\
\hline Kurang & 5 & 18 & 23 & \\
\hline Total & 11 & 34 & 45 & \\
\hline
\end{tabular}

Sumber:Data Primer

Pada tabel di atas dapat di simpulkan bahwa dari 45 responden sebagian besar memiliki pengetahuan kurang dan sikap negatif 18 orang $(78,3 \%)$ tentang pemeriksaan ANC terpadu. Hasil analisa statistik dengan chi-square diperoleh besarnya nilai $\mathrm{X}^{2}$ Hitung (11.025) > $\mathrm{X}^{2}$ Tab $(3,841)$ membuktikan adanya hubungan yang signifikan antara pengetahuan ibu hamil trimester I dengan sikap ibu hamil tentang pemeriksaan ANC terpadu terdapat pada tabel di atas. Hasil analisis uji hubungan menggunakan chisquare, menunjukkan $p$ value sebesar 0,004 $<0,05$ maka artinya $H o$ ditolak dan $H_{I}$ diterima, sehingga menguatkan adanya hubungan pengetahuan ibu hamil trimester I dengan sikap ibu hamil tentang pemeriksaan ANC terpadu. 


\section{Kesimpulan}

Hasil penelitian ini menunjukan tidak adanya kesenjangan antara teori dengan penelitian, dimana apabila pengetahuan baik maka sikapnya juga akan baik, begitupun sebaliknya apabila pengetahuan kurang maka sikap juga akan negatif, hal ini sesuai dengan teori bahwa salah satu komponen pengetahuan merupakan salah satu faktor yang menentukan sikap. (Notoatmodjo, 2007: 8)

Pengetahuan itu sendiri dipengaruhi oleh pendidikan formal. Pengetahuan sangat erat hubungannya dengan pendidikan formal yang dijalani oleh si perempuan. Maka Pendidikan sangat diharapkan bisa membantu semakin luas pula pengetahuannya. Akan tetapi perlu ditekankan, bukan berarti seseorang yang berpendidikan rendah mutlak berpengetahuan rendah juga. (Wawan, 2011: 11)

Hasil penelitian ini menunjukan bahwa setelah dilakukan uji chi-squaretest disimpulkan ada hubungan pengetahuan dengan sikap ibu hamil tentang kunjungan kehamilan (ANC) dengan nilai $p$ sebesar $0,02(p<0,05)$. 
Indah Rahayu

\section{Bibliografi}

A.Wawan \& Dewi M. 2011. Teori dan Pengukuran Pengetahuan, Sikap, dan Perilaku Manusi.Cetakan II. Yogyakarta : Nuha Medika

Efendi, Ferry, Makhfudi. 2009. Keperawatan Kesehatan Komunitas Teori dan Praktik dalam Keperawatan. Salemba Medika. Jakarta.

Hartono, Bambang. 2010. Promosi Kesehatan Di Puskesmas dan Rumah Sakit. Jakarta: Rineka Cipta.

Katzung, Bertram G. 2011. Farmakologi Dasar \& Klinik Edisi 10. Jakarta: Buku Kedokteran EGC.

Notoatmodjo, Soekidjo. 2010. Metode Penelitian Kesehatan. Jakarta: Rineka Cipta.

Pearce, Evelyn. 2017. Anatomi dan Fisiologi Untuk Medis. Jakarta: PT Gramedia Pustaka Utama. 